\title{
Investigation of Mechanical and Structural Properties of Blend Lignin-PMMA
}

\author{
Koray Soygun, ${ }^{1}$ Selçuk Şimşek, ${ }^{2}$ Ersen Yılmaz, ${ }^{2}$ and Giray Bolayır ${ }^{1}$ \\ ${ }^{1}$ Department of Prosthodontics, Faculty of Dentistry, Cumhuriyet University, 58140 Sivas, Turkey \\ ${ }^{2}$ Department of Chemistry, Cumhuriyet University, 58140 Sivas, Turkey \\ Correspondence should be addressed to Koray Soygun; koraysoygun@hotmail.com
}

Received 24 September 2013; Accepted 26 November 2013

Academic Editor: Jim Low

Copyright ( 2013 Koray Soygun et al. This is an open access article distributed under the Creative Commons Attribution License, which permits unrestricted use, distribution, and reproduction in any medium, provided the original work is properly cited.

\begin{abstract}
This in vitro study investigated the mechanical and structural characteristics of lignin-added PMMA resin composites at concentrations of 1,3 , and $5 \%$ by weight. Four sample groups were formed. For the transverse strength test, the specimens were prepared in accordance with ANSI/ADA specification number 12, and for the impact test ASTM D-256 standards were used. With the intent to evaluate the properties of transverse strength, the three-point bending $(n=10)$ test instrument (Lloyd NK5, Lloyd Instruments Ltd., Fareham, Hampshire, UK) was used at $5 \mathrm{~mm} / \mathrm{min}$. A Dynatup $9250 \mathrm{HV}$ (Instron, UK) device was employed for the impact strength measurements $(n=10)$. All resin samples were tested by using a thermomechanical analyzer (Shimadzu TMA 50, Shimadzu, Japan). Mechanical tests revealed that, although the control group was found to have the value of highest transverse strength, the highest impact strength was observed in the PMMA-L-1 group. Upon examining the thermomechanical analysis data, it could be seen that the E value of the control sample was higher than that of all the other samples. Adding lignin powder into PMMA performs plasticizer effect on resin matrix.
\end{abstract}

\section{Introduction}

Polymethyl metacrylate (PMMA) resin is commonly used in the construction of denture base. The fracture of the denture base is a common clinical occurrence in prosthodontic service but still remains adamantly an unsolved problem [14]. In prosthodontics literature many studies [1-7] have proposed to improve the physical and mechanical properties of PMMA resin. Among the various reinforcement approaches, the incorporation of fibers such as glass $[2,5,6,8]$, carbon $[9]$, polyester $[2,10]$, nylon $[2,8]$ and wood $[11,12]$ fibers into the polymer matrix has been found to considerably improve many mechanical and physical properties of denture base resins.

There are many studies which added natural polymers to reinforce different resin matrix, of which lignin is included [11-14]. Lignins (Figure 1) are one of the high molecular weight components of wood and occupy the second place regard to their abundance throughout the world as organic polymeric substances of natural origin [15]. Lignin has long been of interest as a source of inexpensive and renewable adhesives and thermoplastics [16, 17]. However, the commercial utilization of lignin has not been met with success. Lignin is often thought of as a waste product of the paper making process and in the conversion of cellulosics to ethanol. However, it is a potential valuable source of aromatic chemicals, biodegradable polymers, and carbon fibers [18]. Lignins were first used as reinforcing fillers in natural and cured rubbers [19]. Lignins were employed as a reinforcing agent in elastomeric polyethers, polyester amid and polyalkylene glycols [14]. Physico-mechanical properties were reported to be improved for the final product by using lignin $[11,13,14]$.

The aim of the present study was to determine the mechanical and structural properties of lignin powder that was added into PMMA.

\section{Materials and Methods}

Acrylic resin was obtained (Meliodent, Bayer Dental, Newbury, Berkshire, UK) and Kraft Lignin (Lignin, Kraft; 


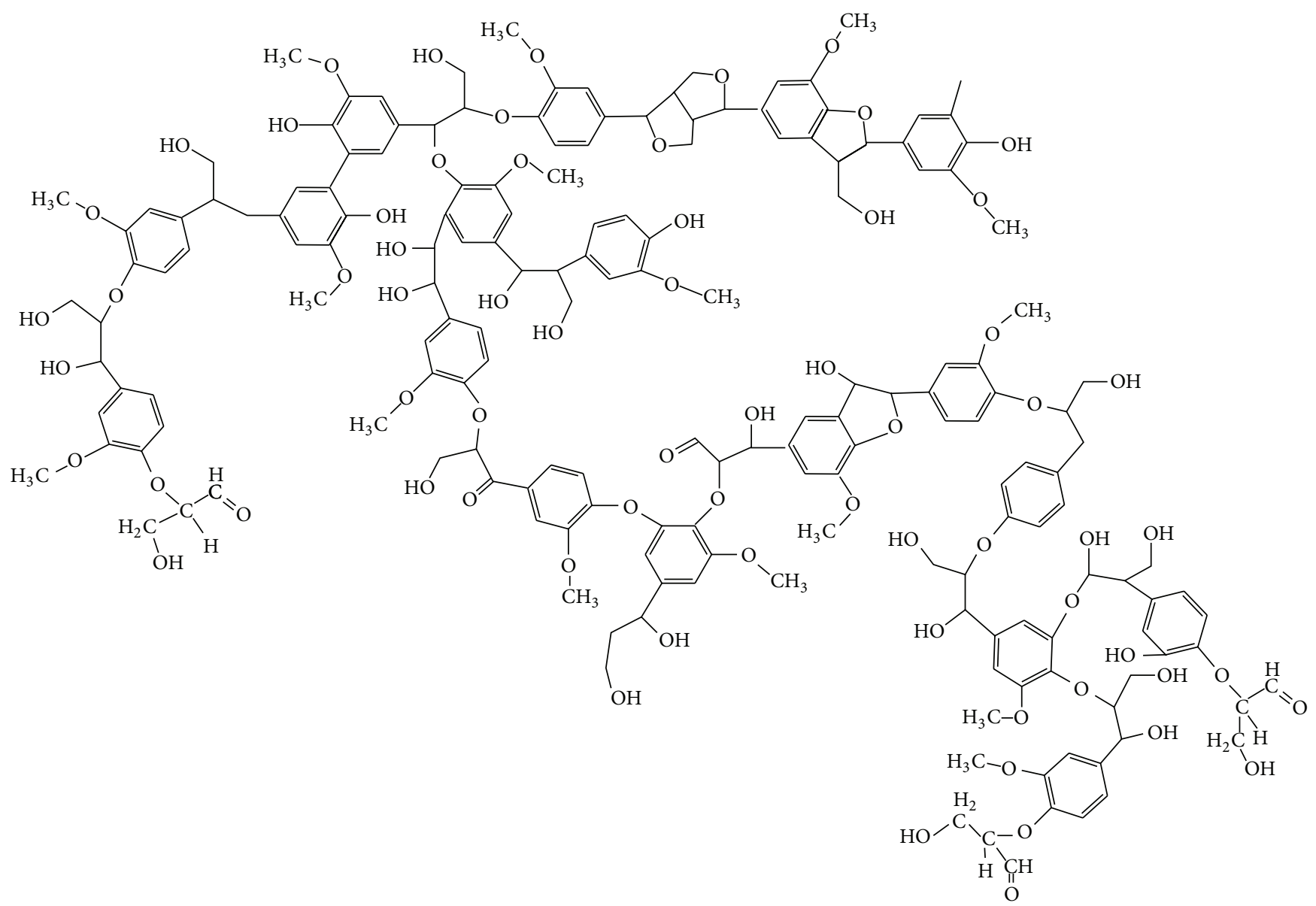

FIGURE 1: Structure of lignin molecule.

INDULIN at; $\left.\left\{\left(\mathrm{CH}_{3} \mathrm{O}\right)(\mathrm{OH}) \operatorname{Ar}\left(\mathrm{C}_{3} \mathrm{H}_{4} \mathrm{O}\right)\right\}_{x}\right)$ was kindly supplied by MeadWestvaco Corp. (USA). All experiments were always performed in duplicates. $\pm 5 \%$ was the limit of experimental error of each of the duplicates, and any experiment that resulted in a value higher than this limit was repeated.

Acrylic resin specimens were prepared at a powder/liquid ratio of $2.34 \mathrm{~g} / \mathrm{mL}$ in accordance with the manufacturer's instructions. After 1-minute mixing and following a dough time of $6 \mathrm{~min}$, the acrylic resin was molded into moulds which had been prepared in advance. After the molding procedure was completed, $5 \mathrm{~min}$ pressure was applied onto the molds under a hydraulic press (Rucker PHI, Birmingham, UK). The molds were then transferred into a $70^{\circ} \mathrm{C}$ water bath for $1 \mathrm{~h}$, and, after that, the polymerization action was performed immediately by keeping them in the boiling water for $30 \mathrm{~min}$. Upon completion of polymerization, the flasks were left to cool at ambient temperature before being opened. Deflasked specimens were manually polished with a 600 -grit water-proof silicon carbide paper under tap water.

PMMA-L composites were prepared at three different concentrations by weight. Four sample groups were constituted as PMMA-L-1 (1\% wt), PMMA-L-2 (3\% wt), and PMMA-L-3 (5\% wt). Four groups, each of which consisted of 10 specimens, were formed for each test. The transverse and impact strength tests were applied as mechanical tests.
Transverse strength was determined by three-point bending test method. The specimens for this test were prepared in $65 \times 10 \times 2.5 \mathrm{~mm}^{3}$ dimensions in accordance with ADA standard number 12 . In preparing the test specimens, a stainless steel mould was used. The standard wax specimens were obtained by pouring the melted pink plate waxes (Modelling Wax, De Trey S.A, Bios Colombes, France) into the isolated mold. The prepared wax specimens were taken into the mold and these wax specimens were removed by melting them and then the molds were made ready for acrylic molding.

Transverse strength was determined by the three-point flexure test in a computer-aided universal test device (Lloyd NK5, Lloyd Instruments Ltd., Fareham, Hampshire, UK). The specimens were placed on supports, located at $50 \mathrm{~mm}$ intervals, and a $5 \mathrm{~mm} / \mathrm{min}$ cracking speed was applied. This amount of speed is enough to crack the specimens. The degree of bending before the cracking occurred was recorded (NEXYGEN, Lloyd Instruments Ltd., Fareham, Hampshire, UK).

Transverse strength values were calculated in $\mathrm{N} / \mathrm{mm}^{2}$ (MPa) by using the following formula:

$$
T_{s}=\frac{3 F l}{2 b d^{2}},
$$


where $T_{s}=$ transverse strength $\left(\mathrm{N} / \mathrm{mm}^{2}\right) ; F=$ applied load $(\mathrm{N}) ; l=$ distance between supports $(\mathrm{mm}) ; b=$ specimen width $(\mathrm{mm}) ; d=$ specimen thickness $(\mathrm{mm})$.

The specimens for the impact strength test were obtained in accordance with ASTM D256 standards and prepared in metal moulds in $55 \times 10 \times 10 \mathrm{~mm}^{3}$ dimensions. The specimens had a V-shaped notch in the middle, with $2 \mathrm{~mm}$ width and $2.54 \mathrm{~mm}$ depth. The specimens were also siliconized (Imprex putty, Arma, Turkey). Polymerization procedures were as described previously. Upon completion of polymerization, the flasks were left to cool at ambient temperature before being opened. Deflasked specimens were manually polished as described above. Impact strength was determined in a Charpy type impact test device (Dynatup $9250 \mathrm{HV}$, Instron, UK). A drop weight of $7.3 \mathrm{~kg}$ (which was equivalent to $12-\mathrm{J}$ energy) was applied to the specimens on the unnotched side.

After the data collection, mean value and standard deviation were calculated with a SPSS statistical software program (14.0 version, SPSS Inc., Chicago, USA). Data were then analyzed by Kruskall-Wallis and Tukey tests for pairwise comparisons of the groups at the 0,05 level of significance.

Following the mechanical tests applied to all the specimen groups, the fractured surfaces were examined under SEM, in the specimens whose acrylic part was broken and $2 \mathrm{~mm}$ sections were obtained by using a water-cooled sectioning device (Buehler IsoMet, Low Speed Saw, USA). The section specimens were then made conductive under the vacuum of $4 \times 10^{-2}$ mbar in a Polaron SC7620 Sputter Coater device by coating with Au-Pd for $15 \mathrm{~s}$ (3 Angstrom coating per second, in total 45 Angstrom). The interface of powder-resin was visualized by surface scanning electron microscope (LEO 440 Scanning Electron Microscope, UK).

The fractured surface of one specimen from each group was also investigated spectroscopically, in order to evaluate the chemical interactions between the materials, by a FTIR spectrometer (Bruker, Vertex 70, Bruker Optics Inc., Ettlingen, Germany). The FTIR spectrometer was used with a diamond crystal Pike MIRacle ATR unit. Fifty scans were obtained and averaged to a resolution of $4 \mathrm{~cm}^{-1}$.

TMA test samples were prepared at $20 \times 5 \times 1 \mathrm{~mm}$ dimensions as recommended by the manufacturer of the instrument (Shimadzu TMA 50, Shimadzu, Japan). Curves demonstrating changes in thermal-mechanical properties with temperature were obtained by using the values produced by the TMA instrument. The stress-strain curves were obtained under nitrogen atmosphere at a heating rate of $10^{\circ} \mathrm{C} \mathrm{min}^{-1}$ and at a loading rate of $10 \mathrm{~g} \mathrm{~min}^{-1}$.

\section{Results and Discussion}

FT-IR spectra of PMMA resin and PMMA-L composite samples are represented comparatively in Figure 2. Upon examining the FT-IR spectra, all of the PMMA-L composite samples showed an $\mathrm{O}-\mathrm{H}$ stretching peak at $3397 \mathrm{~cm}^{-1}$ and a $\mathrm{C}=\mathrm{O}$ streching peak at $1721 \mathrm{~cm}^{-1}$. As the lignin content increased, the intensity of the $\mathrm{C}=\mathrm{O}$ peaks decreased while the intensity of the $\mathrm{O}-\mathrm{H}$ peaks increased. These intensity changes can be attributed to hydrogen bonds that formed between the

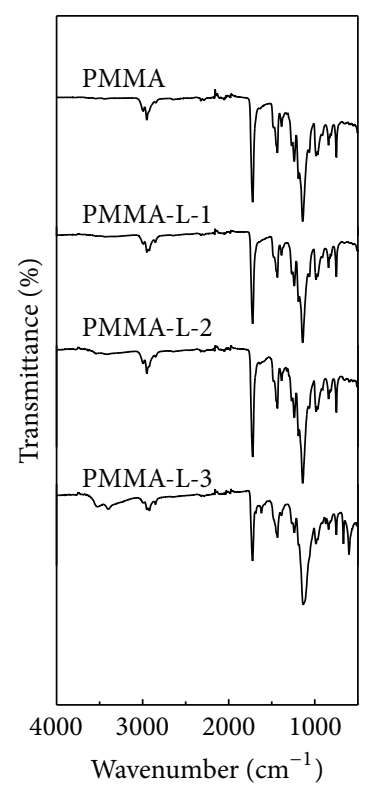

FIGURE 2: The FTIR spectra of composite samples.

lignin and carbonyl groups of PMMA. The absorption peaks at 2920,1386 , and $750 \mathrm{~cm}^{-1}$ belong to aliphatic $\mathrm{C}-\mathrm{H}, \mathrm{C}-\mathrm{O}$, and aromatic rings, respectively.

Structural images of the specimens were obtained by using surface scanning electron microscope. The assessments in lignin-added specimens were made in terms of ligninresin connection and lignin distribution (Figures 3 and 4). PMMA (control) group (Figure 3(a)) has a smooth and compact structure; however, the lignin powder has a spherical structure (Figure 3(b)). In the PMMA-L specimens group (Figures 4(a) and 4(c)), lignin was not spread homogeneously and had no interfacial adhesion with the resin and many gaps between the lignin and the resin matrix were observed. Some cavities appeared to have formed on the interface with the resin matrix. On inspecting (Figures $4(\mathrm{a})-4(\mathrm{c})$ ), a crack line in the lignin powder was observed.

Stress-strain curves of PMMA and lignin-PMMA composites are given in Figure 5. Elastic modulus $(E)$ obtained from these stress-strain curves of PMMA and the prepared composites are listed in Table 1. Below the yield point, elastic modulus $(E)$ can be considered as a criterion for elasticity of a polymer. As seen in Table 1, while the lignin content increases, the elastic modulus of the polymers decreases. Since the elastic modulus and elasticity are inversely related it could be argued that the addition of lignin decreases the elastic modulus of composite resins and hereby improves its plastic properties.

Values obtained from the transverse and impact strength tests were analyzed and the results of statistical evaluation were presented (Table 2). Transverse strength, maximum deflection, and absorbed energy values groups were compared using the Kruskal-Wallis test, and the difference between the groups was found to be significant $(P<0.05)$.

In the present study, when the transverse strength of PMMA and PMMA-L sample groups was compared, it was 


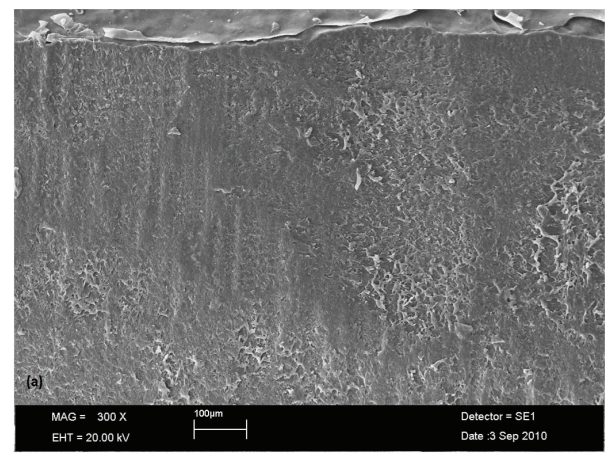

(a)

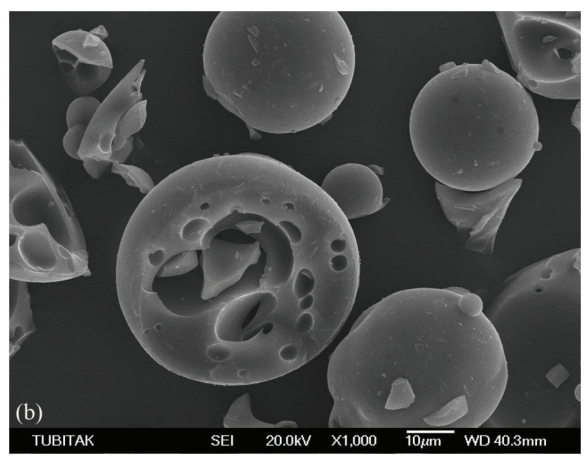

(b)

FIgure 3: SEM image; (a) PMMA (b) lignin.

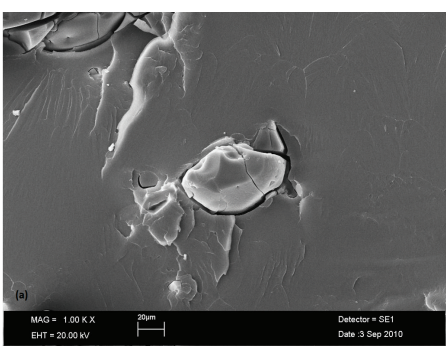

(a)

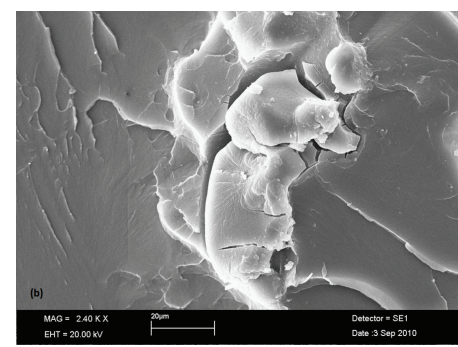

(b)

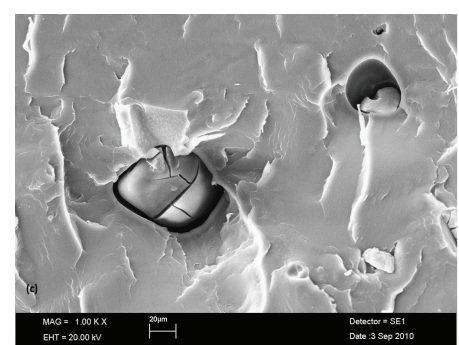

(c)

Figure 4: SEM image. (a) PMMA-L-1; (b) PMMA-L-2; (c) PMMA-L-3.

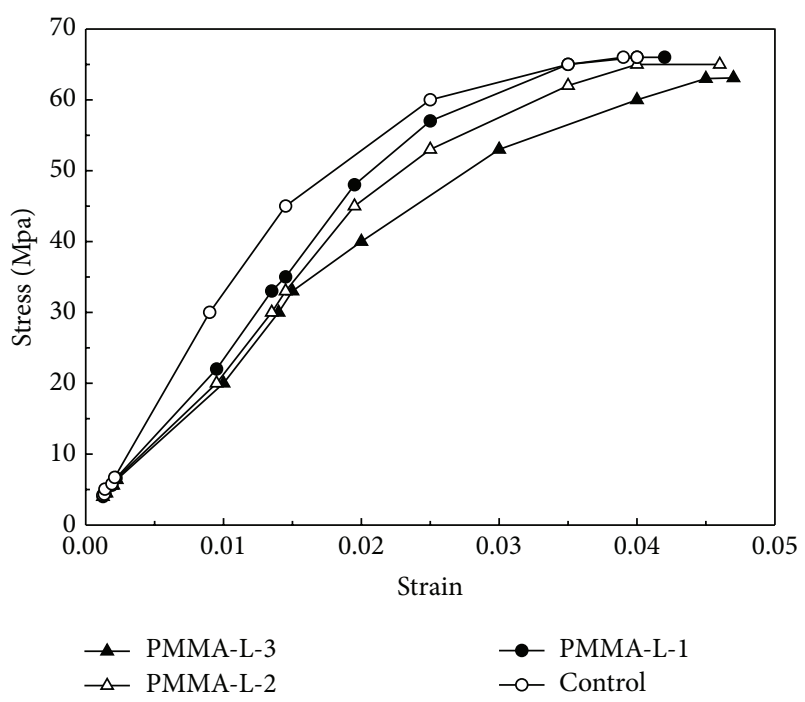

FIGURE 5: Stress-strain curve of composite samples.

found that PMMA (control) sample group had the highest transverse strength $(80.24 \pm 8.69 \mathrm{MPa})$.

Among the PMMA-L groups, the PMMA-L-1 group had a higher transverse strength than the other PMMA-L groups. As the amount of added lignin increased, it was observed in Table 2 that the value of transverse strength decreased. When deflection of the sample groups was evaluated, PMMA-L-3
TABLE 1: Value of elastic modulus of composite samples derived from TMA test.

\begin{tabular}{lc}
\hline Specimen & Elastic modulus (MPa) \\
\hline Control & 2873 \\
PMMA-L-1 & 2739 \\
PMMA-L-2 & 2631 \\
PMMA-L-3 & 2533 \\
\hline
\end{tabular}

had the highest value $(7.73 \pm 1.35 \mathrm{~mm})$. According to deflection and transverse test, an increase in lignin content led to increasing deflection values but also a decrease in transverse strength values of the composites. As seen in SEM images (Figures 4(a)-4(c)), these results could be explained by poor adhesions between the added lignin and the polymer matrix.

In a previous study, wood fiber was added to PMMA at different ratios. It was observed that the control group has better mechanical strength than the fiber added group. Then, by adding binding agent to the fiber added PMMA group, it was observed that their mechanical strength was improved [11].

It has been reported that the mechanical strength of wood fiber added into PMMA resin is not higher than PMMA resin but that of wood fiber treated with bonding agent. Because of increased link between resin matrix and fill, it was emphasized that using improved agent of adhesion between them is needed [20-22]. In the present study, it is considered, that in the specimens to which lignin was added, cavities 
TABLE 2: Value of transverse and impact strength of composite samples.

\begin{tabular}{|c|c|c|c|}
\hline & Transverse strength ${ }^{*}$ & Maximum deflection ${ }^{*}$ & Absorbed energy* \\
\hline Control & $80.24 \pm 8.69$ & $3.38 \pm 0.77$ & $0.26 \pm 0.04$ \\
\hline PMMA-L-1 & $70.92 \pm 5.17$ & $4.97 \pm 0.79$ & $0.89 \pm 0.09$ \\
\hline PMMA-L-2 & $57.63 \pm 5.54$ & $5.15 \pm 0.61$ & $0.87 \pm 0.05$ \\
\hline \multirow[t]{2}{*}{ PMMA-L-3 } & $39.09 \pm 1.38$ & $7.73 \pm 1.35$ & $0.83 \pm 0.09$ \\
\hline & $\mathrm{KW}=17.10$ & $\mathrm{KW}=14.82$ & $\mathrm{KW}=11.64$ \\
\hline
\end{tabular}

${ }^{*}$ Significant at $P<0.05$ for coefficient of correlation. $n=10$.

in between lignin-PMMA could be decreased by bonding agents.

Many researchers have used the impact strength tests in order to test acrylic resin and to determine the effects of environmental conditions or continuous, trimmed fibers. This test has also been used for the comparison of different denture base resins. The impact strength is not the real property of a material because the dimension of the specimen is dependent on factors such as the existence and depth of the notches, the loading configuration, and the speed of impact. The frenulum areas damaging the integrity of acrylic dentures are the ones where the stress concentration is high. In order to stimulate this, the specimens of impact test are prepared in notches [23]. In our study, we also prepared the specimens for impact test according to the Charpy test method.

According to impact test results, the control group specimens have the lowest energy absorption value $(0.26 \pm$ $0.04 \mathrm{~J}$ ) and these values were significantly much higher in lignin-added specimens. As seen in the table PMMA-L-1, which contained $1 \%$ lignin by weight, has the highest energy absorption value $(0.89 \pm 0.09 \mathrm{~J})$ and, as the lignin content increased, the energy absorption values decreased. Although higher lignin content decreases the energy absorption values of the specimens, the decrease was not statistically significant $(P>0.05)$. Increasing energy absorption values at ligninadded groups could be explained by hydrogen bonds that formed between lignin and matrix.

\section{Conclusions}

In spite of the fact that added lignin powder, increases the impact strength of PMMA resin matrix, it causes a decrease in transverse strength and elastic modulus. It could be clearly seen that lignin performs a plasticizer effect on PMMA resin matrix. Furthermore, advanced clinical grade investigations are required.

\section{References}

[1] D. C. Jagger, R. G. Jagger, S. M. Allen, and A. Harrison, "An investigation into the transverse and impact strength of "high strength" denture base acrylic resins," Journal of Oral Rehabilitation, vol. 29, no. 3, pp. 263-267, 2002.

[2] O. M. Doğan, G. Bolayir, S. Keskin, A. Doğan, B. Bek, and A. Boztuğ, "The effect of esthetic fibers on impact resistance of a conventional heat-cured denture base resin," Dental Materials Journal, vol. 26, no. 2, pp. 232-239, 2007.
[3] H. D. Stipho, "Effect of glass fiber reinforcement on some mechanical properties of autopolymerizing polymethyl methacrylate," The Journal of Prosthetic Dentistry, vol. 79, no. 5, pp. 580584, 1998.

[4] M. K. Marei, "Reinforcement of denture base resin with glass fillers," Journal of Prosthodontics, vol. 8, no. 1, pp. 18-26, 1999.

[5] M. Nakamura, H. Takahashpi, and I. Hayakawa, "Reinforcement of denture base resin with short-rod glass fiber," Dental Materials Journal, vol. 26, no. 5, pp. 733-738, 2007.

[6] T. Kanie, K. Fujii, H. Arikawa, and K. Inoque, "Flexural properties and impact strength of denture base polymer reinforced with woven glass fibers," Dental Materials, vol. 16, no. 2, pp. 150$158,2000$.

[7] D. L. Gutteridge, "The effect of including ultra-high-modulus polyethylene fibre on the impact strength of acrylic resin," British Dental Journal, vol. 164, no. 6, pp. 177-180, 1988.

[8] O. M. Doğan, G. Bolayır, S. Keskin, A. Doǧan, and B. Bek, “The evaluation of some flexural properties of denture base resin reinforced with various aesthetic fibers," Journal of Materials Science, vol. 19, pp. 3343-3348, 2008.

[9] C. K. Shreiber, "Polymethyl metacrylate reinforced with carbon fibers," British Dental Journal, vol. 130, pp. 29-30, 1971.

[10] S. Y. Chen, W. M. Liang, and P. S. Yen, "Reinforcement of acrylic denture base resin by incorporation of various fibers," Journal of Biomedical Materials Research, vol. 58, pp. 203-208, 2001.

[11] D. Maldas, B. V. Kokta, and C. Deneault, "The mechanical properties of wood fiber-reinforced polymethylmetacrylate," International Journal of Polymeric Materials and Polymeric Biomaterials, vol. 12, pp. 297-323, 1989.

[12] S. Mishra and J. B. Naik, "Mechanical properties of wood polymer composites prepared from agro-waste and HDPE," Polymer, vol. 44, no. 3, pp. 511-522, 2005.

[13] H. D. Rozman, R. N. Kumar, M. R. M. Adlli, A. Abusamah, and I. Z. A. Mohd, "The effect of lignin and surface activation on the mechanical properties of rubberwood-polypropylene composites," Journal of Wood Chemistry and Technology, vol. 18, no. 4, pp. 471-490, 1998.

[14] D. K. Setua, M. K. Shukla, V. Nigam, H. Singh, and G. N. Mathur, "Lignin reinforced rubber composites," Polymer Composites, vol. 21, no. 6, pp. 988-995, 2000.

[15] F. S. Chakar and A. J. Ragauskas, "Review of current and future softwood kraft lignin process chemistry," Industrial Crops and Products, vol. 20, no. 2, pp. 131-141, 2004.

[16] J. F. Kadla and S. Kubo, "Lignin-based polymer blends: analysis of intermolecular interactions in lignin-synthetic polymer blends," Composites A, vol. 35, no. 3, pp. 395-400, 2004.

[17] R. Pucciariello, V. Villani, C. Bonini, M. D’Auria, and T. Vetere, "Physical properties of straw lignin-based polymer blends," Polymer, vol. 45, no. 12, pp. 4159-4169, 2004. 
[18] D. R. Crist, R. H. Crist, and J. R. Martin, "A new process for toxic metal uptake by a kraft lignin," Journal of Chemical Technology and Biotechnology, vol. 78, no. 2-3, pp. 199-202, 2003.

[19] E. G. Lyubeshkina, "Lignins as components of polymeric composite materials," Russian Chemical Reviews, vol. 52, pp. 1196-1224, 1983.

[20] O. Karacaer, A. Doğan, O. M. Doğan, and A. Usanmaz, "Dynamic mechanical properties of dental base material reinforced with glass fiber," Journal of Applied Polymer Science, vol. 85, no. 8, pp. 1683-1697, 2002.

[21] G. S. Solnit, "The effect of methyl methacrylate reinforcement with silane-treated and untreated glass fibers," The Journal of Prosthetic Dentistry, vol. 66, no. 3, pp. 310-314, 1991.

[22] P. K. Vallittu, "Comparison of two different silane compounds used for improving adhesion between fibres and acrylic denture base material," Journal of Oral Rehabilitation, vol. 20, no. 5, pp. 533-539, 1993.

[23] G. Zappini, A. Kammann, and W. Wachter, "Comparison of fracture tests of denture base materials," The Journal of Prosthetic Dentistry, vol. 90, no. 6, pp. 578-585, 2003. 

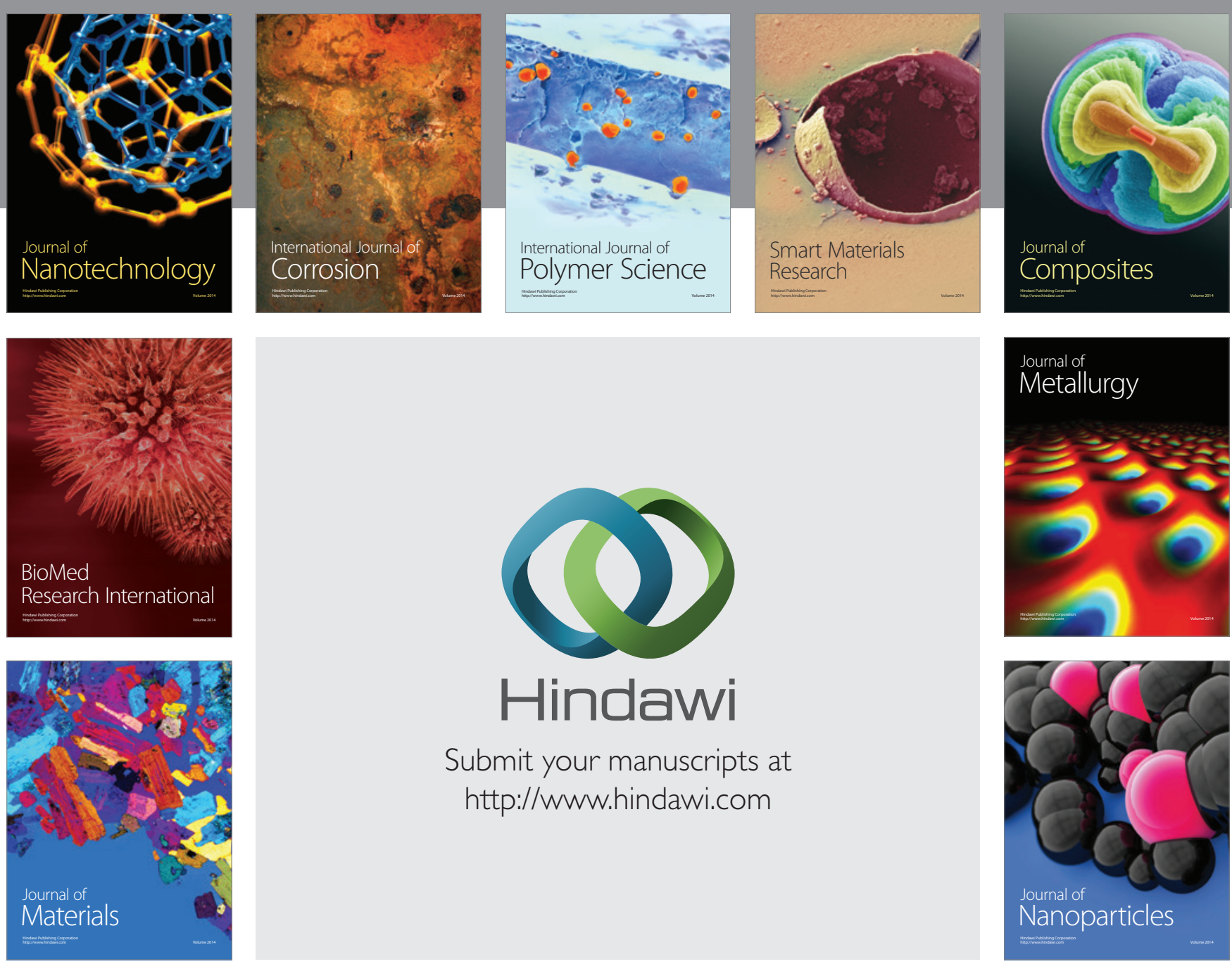

Submit your manuscripts at http://www.hindawi.com
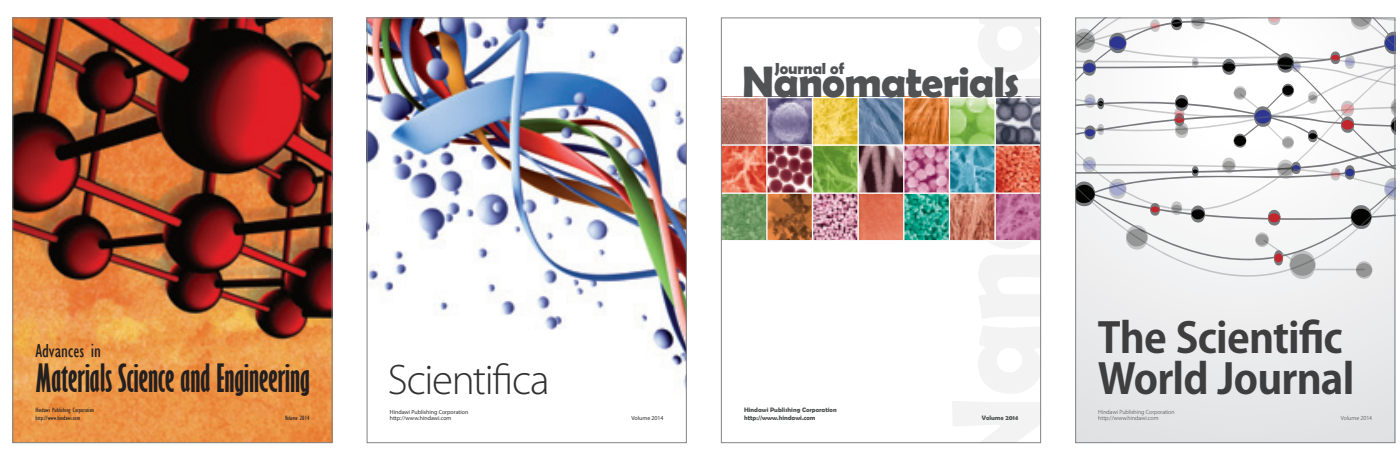

\section{The Scientific World Journal}
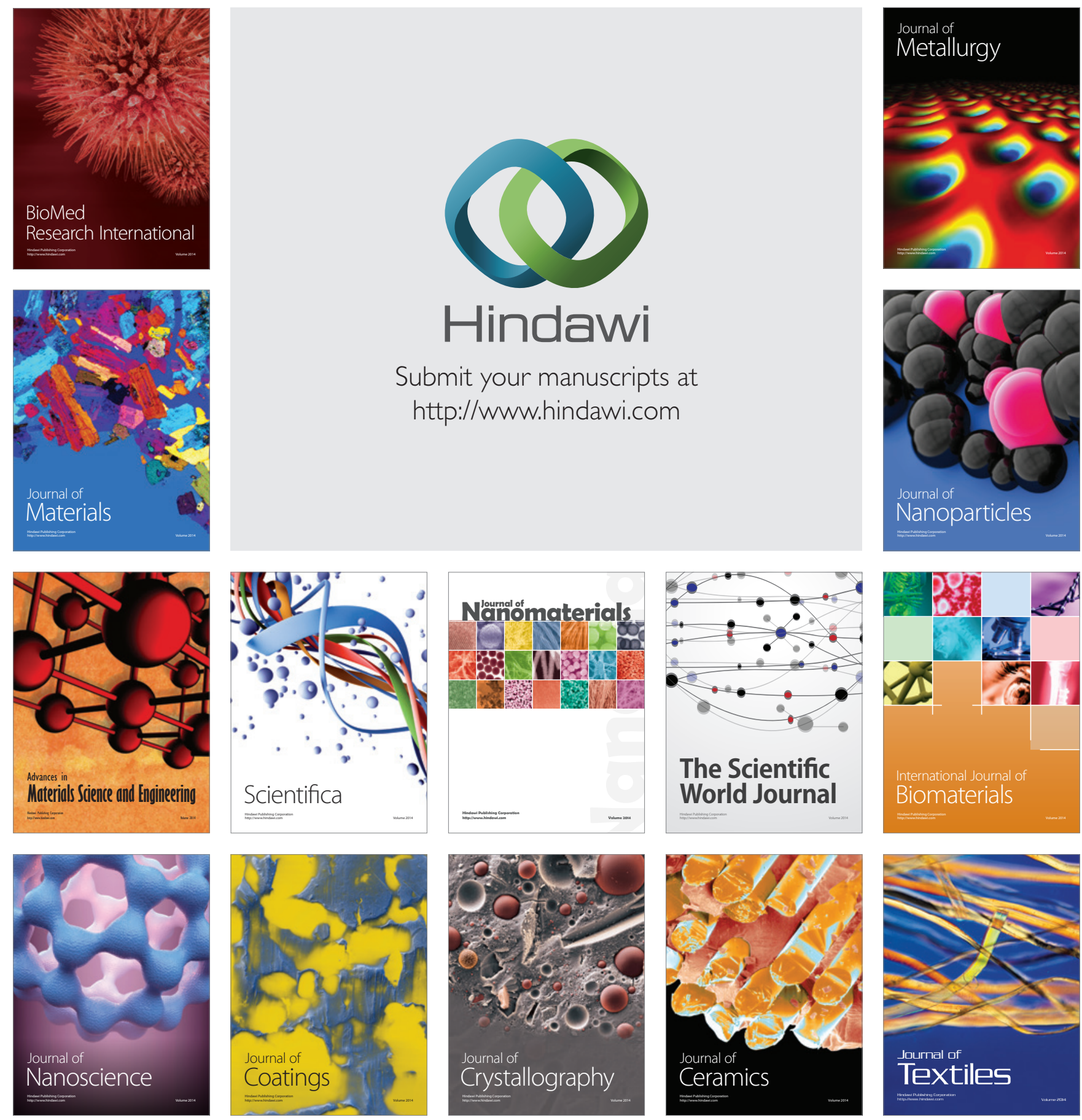